\title{
Shark Side of the Moon: Are Shark Attacks Related to Lunar Phase?
}

\author{
Lindsay A. French ${ }^{1,2}$, Stephen R. Midway ${ }^{3 *}$, David H. Evans ${ }^{4}$ and George H. Burgess ${ }^{2}$ \\ ${ }^{1}$ Fisheries and Aquatic Sciences Graduate Program, School of Forest Resources and Conservation, University of Florida, \\ Gainesville, FL, United States, ${ }^{2}$ Florida Program for Shark Research, Florida Museum of Natural History, University of Florida, \\ Gainesville, FL, United States, ${ }^{3}$ Department of Oceanography and Coastal Sciences, Louisiana State University, Baton \\ Rouge, LA, United States, ${ }^{4}$ Department of Biology, University of Florida, Gainesville, FL, United States
}

\section{OPEN ACCESS}

Edited by: Jeffrey C. Mangel, Prodelphinus, Peru

Reviewed by: Natascha Wosnick Federal University of Paraná, Brazil Oliver J. D. Jewell, University of Western Australia, Australia

*Correspondence. Stephen R. Midway smidway@lsu.edu

Specialty section: This article was submitted to Marine Megafauna, a section of the journal

Frontiers in Marine Science

Received: 21 July 2021 Accepted: 09 November 2021 Published: 01 December 2021

Citation:

French LA, Midway SR, Evans DH and Burgess GH (2021) Shark Side of the Moon: Are Shark Attacks

Related to Lunar Phase?

Front. Mar. Sci. 8:745221. doi: 10.3389/fmars.2021.745221
Animals across taxa have shown behaviors linked to moon phase (or the proxy of lunar illumination), and marine organisms are well-documented to calibrate certain activities with the moon. Few studies have looked at a possible connection between moon phase and shark attacks on humans, and the results have been preliminary or lacking relationships. We used nearly 50 years of shark attack data from across the globe to test for a relationship between shark attacks and moon phase. We examined factors of geography, shark species, and outcome of attack. From 12 relationships that we tested (totaling 120 comparisons), we found 12 significant outcomes, of which five were positive (i.e., more attacks than expected) and seven were negative (i.e., fewer attacks than expected). Specifically, all the instances of more shark attacks than expected occurred at lunar illumination $>50 \%$, while all the instances of fewer shark attacks than expected occurred at lunar illumination of $<50 \%$. The findings presented here provide global evidence that shark attacks may be related to moon phase, and such information could be useful toward evaluating attack risk and developing recommendations for water-based recreational activities.

Keywords: lunar illumination, moon phase, shark attack, beach safety, shark behavior

\section{INTRODUCTION}

The behavior of many animal species has been linked to phases of the moon [e.g., seabirds (Tarlow et al., 2003), amphibians (Grant et al., 2013), and mammals (Prugh and Golden, 2014)]. Many marine animals have well-documented lunar-associated rhythms in their movements [e.g., giant manta ray (Dewar et al., 2008) and gray reef shark (Vianna et al., 2013)], reproduction [e.g., damselfishes (Foster, 1987), various fish species (Takemura et al., 2010), Acropora spp. (Kaniewska et al., 2015), and corals (Zoccola and Tambutte, 2015)], abundance [Bonneville cisco Prosopium gemmifer (Luecke and Wurtsbaugh, 1993) and various mangrove tidal creek fish species (Ramos et al., 2011)], and catch rates [e.g., marine pelagic fishes (Lowry et al., 2007; Poisson et al., 2010), striped marlin Tetrapturus audax (Ortega-Garcia et al., 2008), and various mangrove tidal creek fish species (Ramos et al., 2011)]. Sharks, in particular, have well-documented lunar-associated rhythms in their movements (Graham et al., 2006; Vianna et al., 2013), catch rates (Wintner and Kerwath, 2018; Guyomard et al., 2019), and natural feeding patterns (Fallows et al., 2016). Moon phase itself may have a direct or indirect effect on behaviors. For example, a direct effect of moon phase may be the moon's night-time illumination that changes an organism's behavior based on visual cues, while an indirect effect might be the moon's effect on tides or electromagnetic fields 
(Bevington, 2015), which then influence how organisms behave. Shark species implicated in bites on humans predominantly are highly mobile pelagic or epibenthic, meso- or apex-predators that potentially benefit from increased light intensity/duration, more robust tidal flow, and often from greater localized abundances and uncommonly encountered behaviors of lunar-influenced prey species that facilitate (and may even prompt) accelerated predatory behaviors (Midway et al., 2019). Regardless of the type of effect, moon phase is a well-established influence on animal behaviors, especially those in marine environments.

Shark attacks on humans is an animal behavior of great public interest (Hazin et al., 2008; Burgess et al., 2010; West, 2011), but the prime causes of the phenomenon still require study (Baldridge, 1988; McCosker and Lea, 2006; Hazin et al., 2008). Recent work has shown evidence for an increase in shark attacks where human populations have increased (Midway et al., 2019); however, this is only part of the story as spatiotemporal environmental factors likely play a role. A recent study by Wintner and Kerwath (2018) suggests that environmental factors, such as lunar phase, sea surface temperature, and water visibility, can be used to predict the abundance of sharks within a bather-protection area of the coastline in KwaZulu-Natal, South Africa. However, the effect of human-shark interactions within the bather-protection area were not recorded in this study. Using data in the International Shark Attack File (ISAF), Burgess et al. (2010) suggested that there is a correlation between lunar cycles and shark attacks on humans. However, this study was limited to Volusia County, FL, United States, which is known for shark attacks (popularly referred to as "the shark bite capital of the world") but may not adequately capture this global phenomenon. A subsequent study by Ritter et al. (2013) found no correlation between worldwide shark attacks on humans and lunar cycles, although this study used limited data (and not data from the ISAF). Shark attacks are fortunately infrequent events; however, their uncommonness means they can present analytical challenges, especially at small spatio-temporal scales.

In this study we used ISAF data on worldwide shark attacks to analyze possible relationships between shark attacks and lunar phase. We wanted to answer the question of whether shark attacks were more or less frequent during different phases of the moon (as represented by lunar illumination). We sought to evaluate this possible relationship by considering geography of the attacks, reported species involved in the attack, and the outcome of the attack in terms of fatality.

\section{MATERIALS AND METHODS}

\section{Data Sources and Preparation}

Data used in this study are curated in the International Shark Attack File (ISAF), located at the Florida Museum of Natural History, University of Florida, Gainesville, FL, United States. Established in 1958, the ISAF is one of the most comprehensive data resources on shark attacks and currently contains more than 6,500 individual investigations (records) documenting historic attacks dating back to the 1500s. Records are broadly categorized based on level of confirmation (shark involvement confirmed, shark involvement not confirmed, data insufficient) and classification type (unprovoked, provoked, post-mortem scavenge, air-sea disaster, boat attack, doubtful). As has been the long-established standard, only confirmed unprovoked attacks on live humans occurring in the shark's native environment are used in data analyses examining naturally occurring interactions.

We examined confirmed unprovoked shark attacks from 19702016, the period with the greatest number of shark-human interactions and of the most complete ISAF documentation. Each attack was paired (using the date and location of attack) with lunar phase data, which was sourced using data services from the United States Naval Observatory's Astronomical Applications Department. ${ }^{1}$ The Astronomical Application Department uses noon as a standard time to compute the percent of the moon's surface illuminated (lunar illumination hereafter) occurring in the world's time zones. Lunar illumination data is interval data (a proportional value falling within the interval 0-1) and provides a more quantitative measure than categorical or ordinal moon phase. For reference, a full moon occurs at $100 \%$ illumination, a new moon occurs at $0 \%$ illumination, and first and last quarters occur at 50\% illumination (see text footnote 1). Because shark attacks can occur at any time (i.e., are not restricted to nighttime, and in fact the vast majority occur during the day), we do not ascribe a direct visual linkage between lunar illumination and shark attacks. Rather, lunar illumination is simply a reliable and quantitative proxy for moon phase, which includes not only the potential effect of illumination but also effects of gravity (tides) and electromagnetic fields.

Lunar illumination cycles do not advance at the same rate. In other words, the moon spends more time at and around the new and full phases than in the waxing and waning phases. The moon may spend 9 days around the full phase (measured by $>80 \%$ illumination, followed by only 6 days to advance to illumination $<20 \%$ and the new phase (Figure 1A). In total, although the new and full phases (as measured by $0-10 \%$ and $90-100 \%$ ) may only represent $20 \%$ of the illumination intervals, the moon spends around $40 \%$ of its cycle in and around these extremes (Figure 1B). These lunar phase dynamics mean it is important to understand the disproportionate time the moon spends in different phases, because this non-uniform distribution of time needs to be accounted for when comparing lunar illumination to shark attacks.

In addition to generating reference lunar illumination data and shark attack records, we also sought to evaluate the co-factors of geography, shark species, and outcome of attack (fatal or nonfatal).

\section{Analysis}

Shark attack data constitutes post hoc incident reports and there is obviously no probabilistic design or inferential framework available for the analysis. In other words, there are no records of "no shark attack" that can balance the reported attacks and permit different outcomes to be modeled against different predictors,

\footnotetext{
${ }^{1}$ https://www.usno.navy.mil/USNO/astronomical-applications/data-services
} 


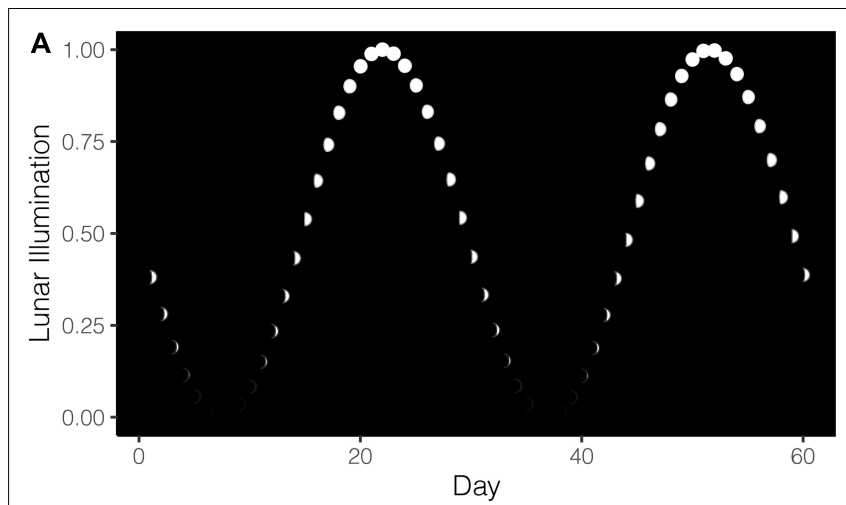

B

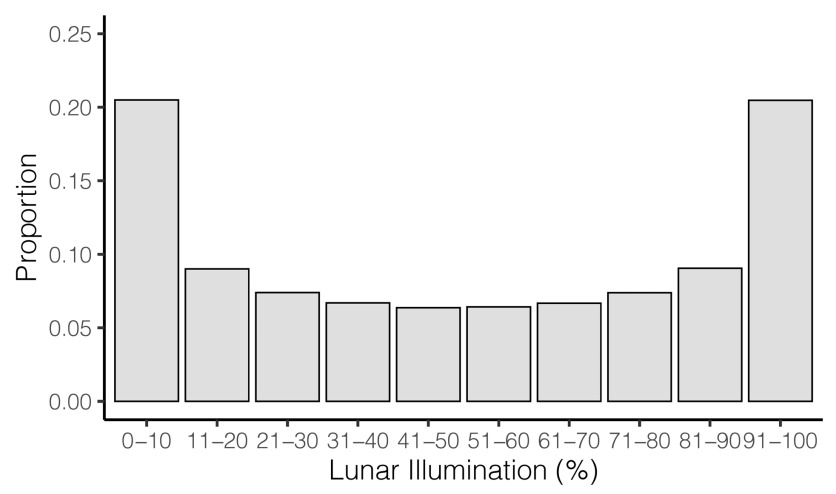

FIGURE 1 | (A) Illustration of the lunar illumination cycle where the moon is depicted as white dots. (B) Proportion of time (days) the moon spends in different lunar illumination deciles. No shark attacks are included here; this is simply to reference the non-uniform temporal distribution of lunar illumination that serves as the expected values in the analyses.

as might be done with conventional linear models. Although emerging techniques such as pseudo-absence generation exist, it is not practical in our study design to consider absences across a global scale over 50 years and for multiple species. Rather, we are limited to quantitative descriptions and frequency analyses in order to understand any effect of the factors in question on shark attacks. We opted to use a Chi-squared test, which is a simple, yet powerful, way to test for differences among categorical groups with different frequencies. Chi-squared Goodness-of-fit tests were used, because we were only examining one factor at a time across the 10 lunar illumination deciles.

We ran a total of 12 Chi-squared tests (including 120 individual comparisons) that were clustered into four thematic groups. The first group was continents, which included North America ( $n=1,095$ shark attacks), Australia ( $n=307$ shark attacks), Africa ( $n=280$ shark attacks), and the Pacific Ocean Islands ( $n=260$ shark attacks; not a continent, but comparable large geographic area of interest). These four continents were selected based on having $>100$ reported shark attacks in each of their coastal waters. Although continent is a large and variable spatialization, examining the factor of continent might permit the detection of any effects that are correlated by geography. The second group was shark species, which included white sharks (Carcharodon carcharias, $n=279$ shark attacks), tiger sharks (Galeocerdo cuvier, $n=98$ shark attacks), and bull sharks (Carcharhinus leucas, $n=87$ shark attacks). These three sharks have, by far, the most confirmed identifications and are well documented in shark attacks. Although dozens of other shark species occur in the ISAF database, most of the species are reported $<5$ times, with most shark attack incidents being classified as "species unknown" due to insufficient evidence required to identify the specific species. Therefore, these cases are not suitable for species-specific frequency analyses. The factor of shark species permitted us the chance to detect any effects that might be species-specific. The third group was attack outcome, which included either the non-fatal ( $n=1,926$ shark attacks) or fatal ( $n=230$ shark attacks) outcome experienced by the human victim. By analyzing each outcome, we created the opportunity to understand whether the severity of the attack might be related to lunar illumination.

Finally, the last group we examined was United States regions, which included the east coast $(n=882$ shark attacks, including the states of Florida, Georgia, South Carolina, North Carolina, Virginia, Delaware, and New Jersey), Hawaii ( $n=147$ shark attacks), and the west coast ( $n=128$ shark attacks, including the states of California, Oregon, and Washington). Despite already including a geographic factor (continents), the large number of attacks in US waters permitted the opportunity to look at geography in a closer way. Examining US regions also creates a more ecologically realistic geographic scenario than looking at some entire continents. For example, the habitats, shark species, and oceanic conditions of the United States west coast, United States east coast, and Hawaii are all very unique, and given the adequate sample sizes in the database, warrant individual analyses. Although several attack records many have been analyzed in more than one Chi-squared test, it was not possible or desirable to run (multi-factor) Chi-squared tests of independence due to reduced sample sizes, in addition to the fact that we wanted to examine the factors in isolation to understand their potential effect.

An overall Chi-squared test statistic was not particularly important to us because it did not convey any information about the specific lunar illumination phases and $p$-values on the Chi-squared test statistic do not preclude informative categories. (Comparable to an analysis of variance, or ANOVA, a significant $p$-value informs whether one or more group differs, but not which group(s) differ). Therefore, we evaluated the standardized residuals for each lunar illumination phase because (1) standardized residuals provide phase-specific information about the observed number of attacks compared to the expected number of attacks, and (2) standardized residuals follow a standard normal distribution and their magnitude can easily be evaluated using a simple $Z$-score approach (i.e., confidence intervals). As such, we determined each standardized residual $<-1.96$ to be negatively significant (the observed value was less than the expected value) and each standardized residual $>1.96$ to be positively significant (the observed value was greater than the expected value). Standardized residuals $-1.96<x<1.96$ were considered to have observed values that were not statistically different from the expected value. 


\section{RESULTS}

Overall, we ran 12 Chi-squared tests that tested 120 individual comparisons and found 12 lunar illumination categories with a significant standardized residual-five significantly positive and seven significantly negative. The first set of Chi-squared models looked at each of four continents. Three of four continentsNorth America, Pacific Ocean Islands, and Australia-all had at least one significant lunar illumination phase. North America (11-20\% and 31-40\%; Figures 2A, 3A) and the Pacific Ocean Islands (0-10\%; Figures 2B, 3B) each had at least one negative standardized residual. Africa had no significant effects (Figures 2C, 3C), while Australia had one positive standardized residual (61-70\%; Figures 2D, 3D). Fatal outcomes had no significant standardized residuals (Figures 2E, 3E), whereas nonfatal outcomes had one significantly negative category (11-20\%) and one significantly positive category (61-70\%; Figures 2 F, 3F). Shark species had little overall effect on attacks by lunar illumination. Neither bull shark nor tiger shark attacks had any relationship to lunar illumination phase (Figures $\mathbf{2 G}, \mathbf{H}$, $\mathbf{3 G}, \mathbf{H})$, while white sharks had only one significant lunar illumination phase, which was a negative effect on the $0-10 \%$ lunar illumination category (Figures 2I, 3I). Each of the three United States regions had at least one lunar illumination phase significantly different from its expectation. The United States east coast had a negative effect of 31-40\% (Figures 2J, 3J), the United States west coast had a negative effect of $11-20 \%$ and two positive effects in $51-60 \%$ and $61-70 \%$ (Figures $2 \mathbf{K}, 3 \mathbf{K}$ ), and Hawaii had one positive effect in 51-60\% lunar illumination (Figures 2L, 3L).

Another result of note was the bifurcation of positive and negative standardized residuals in different ranges of lunar illumination. All seven of the significantly negative results were at lunar illumination phases $<40 \%$, with most occurring in the $0-20 \%$ range. In contrast, all of the significantly positive results were at lunar illumination phases $>50 \%$, with most occurring in the $61-70 \%$ phase. In other words, anytime an observed number of shark attacks was significantly lower than the expected number, it was during very low lunar illumination, whereas anytime an observed number of shark attacks was significantly higher than the expected number, it was during high lunar illumination phases.

\section{DISCUSSION}

This is the first global study to report an effect of lunar illumination on shark attacks. Although shark attack data do not permit the use of conventional inferential statistical approaches, we used a simple and robust quantitative measure of comparing observed shark attacks to expected shark attacks, which estimated numerous instances of more or less shark attacks than were expected. Significant effects were most common in models that looked at United States regions. In some ways this is not surprising because the United States regions we examined are very distinct from each other and represent unique coastal and oceanic systems. Ocean and shark dynamics in Florida are very different from the ocean and shark dynamics in California, suggesting that these areas may have independent relationships or responses to lunar illumination. Interestingly, species-specific analysis showed the fewest instances of significant moon phases (only one significant effect for white sharks). This was somewhat surprising because moon effects in other marine animals are often reported to be species-specific (Takemura et al., 2010), and as such it would not have surprised us to see different patterns of effects in different shark species. What may likely be going on at the species level is that because the shark species we examined are cosmopolitan in their distribution, different local effects could be adding variability to any overall species effect. For example, attacks by white sharks are commonly reported in the United States west coast, South Africa, and Australia (Midway et al., 2019). If one or more of those locations has its own dynamic (and especially if two or more have effects in the opposite direction), such local-scale noise could eliminate any overall species effect. If lunar light indeed has a direct effect on shark behavior, the significant moon phase effect detected for white sharks may be explained by this species' habit of feeding mostly at or near the water surface, targeting meso- and epipelagic prey items (predominantly sea-mammals in much of its range), which is facilitated by prey silhouettes observed when attacking from below and behind (Burgess and Callahan, 1996). Humans, like pinnipeds and cetaceans, are, of course, water surface-oriented air-breathers. While we are fortunate that shark attacks are not more common, their general rarity prohibits most multi-factor analyses because subgroup sample sizes are typically below levels accepted for statistical analyses.

Our most interesting finding was the exclusivity of negative effects only occurring at lunar illumination $<40 \%$ and positive effects only occurring at lunar illumination $>50 \%$. In other words, fewer shark attacks than expected only occurred at lower values of lunar illumination while more shark attacks than expected only occurred at higher values of lunar illumination. Although this is not firm evidence of shark attacks preferentially occurring during periods of greater lunar illumination (i.e., a full moon), these results are the first global evaluation to report any evidence of shark attacks correlated to moon phase, and as such warrant further investigation. We recognize the possibility that some of the effects we found could be redundant, insofar as the group analyses all subset a shared dataset (meaning that if an effect were strong enough it could show up in more than one subset of the data). Despite this possibility, we doubt that any effects are redundant. We designed the four groups that we analyzed to not only have underlying questions to them, but to represent a different subset of data than was used in any other analysis. For example, attacks by white sharks dominate the United States west coast, and attacks by tiger sharks dominate Hawaii. Despite the known correlation between these species and locations, individual models for white sharks and the United States west coast, and tiger sharks and Hawaii shared no significant lunar illumination phases. If there were some underlying effect and/or the subset data were very similar, we would have seen the same significant lunar phases in both models. The fact that they did not show this-and in fact showed significant effects for different phases-provides strong evidence that the groups we used were not closely related to each other (data-wise) and the subsequent significant effects were unique 


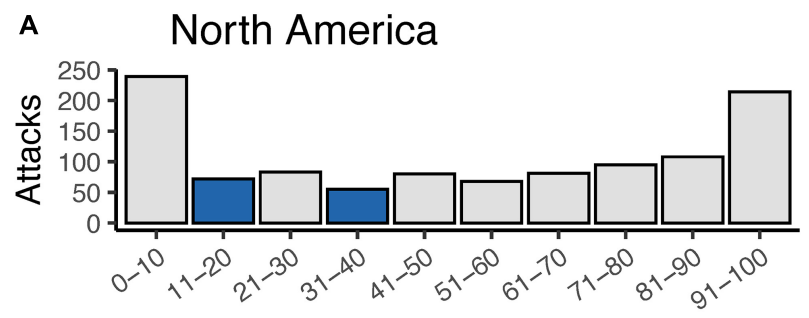

B Pacific Ocean Islands

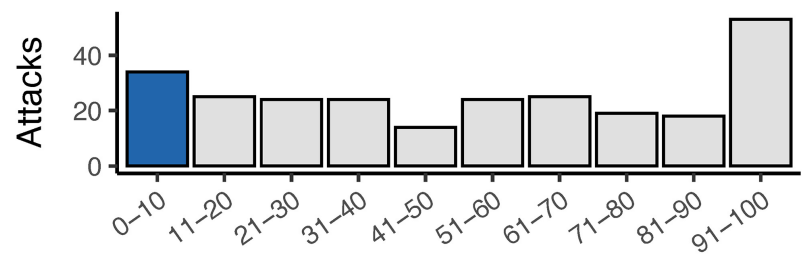

c Africa

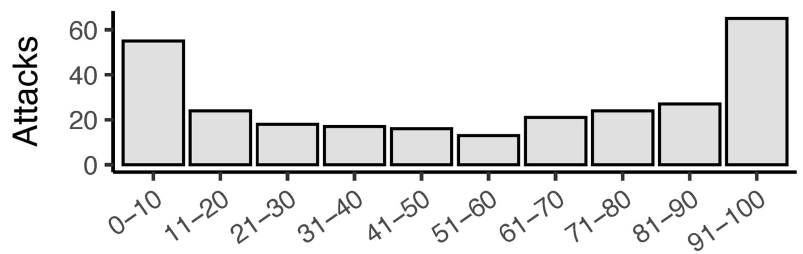

D Australia

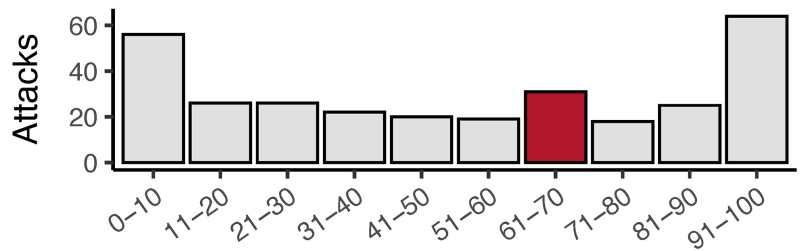

E

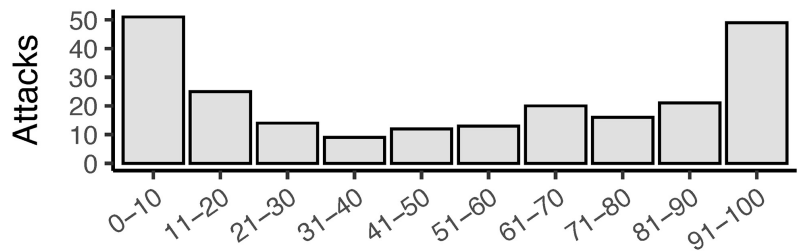

F

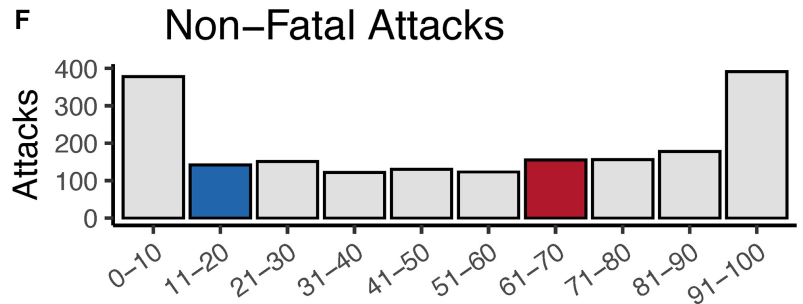

Lunar Illumination (\%)
G Bull Shark

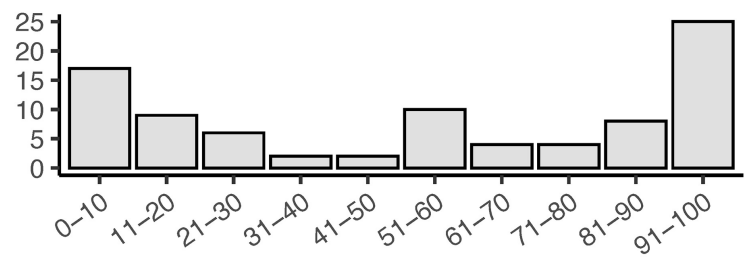

H Tiger Shark

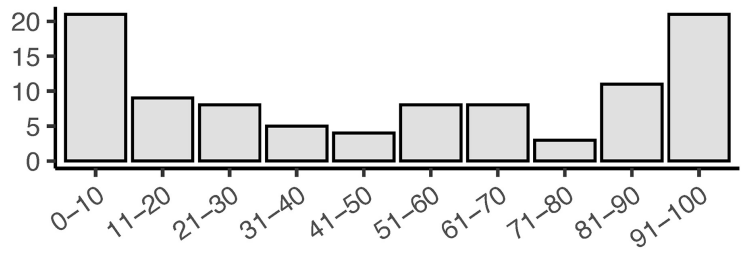

I White Shark

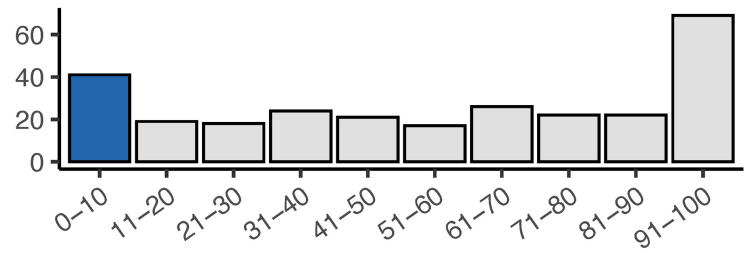

J US East Coast

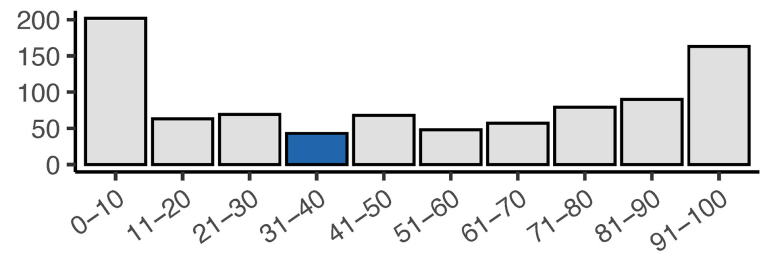

k US West Coast

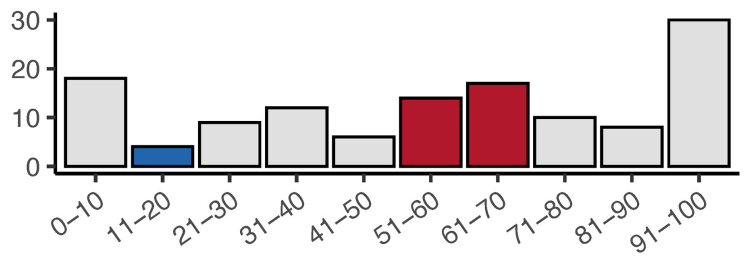

L Hawaii

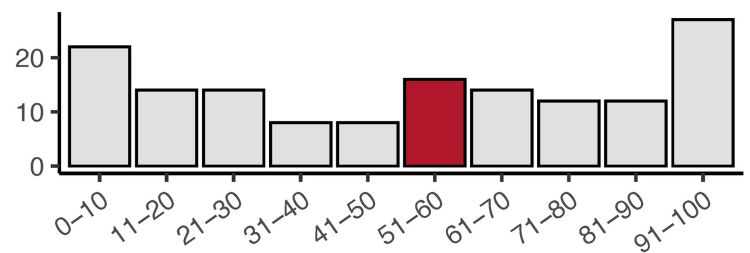

Lunar Illumination (\%)

FIGURE 2 | Counts of shark attacks by lunar illumination deciles split by continental geographic regions (A-D), shark attack outcome (E,F), shark species (G-I), and United States regions (J-L). Gray bars represent counts of attacks that did not statistically differ from the expected count when analyzed with a Chi-squared test. Blue bars represent shark attack counts that were significantly less than the expected number of counts for a given lunar illumination decile, while red bars represent shark attack counts that were significantly greater than the expected number of counts for a given lunar illumination decile. 


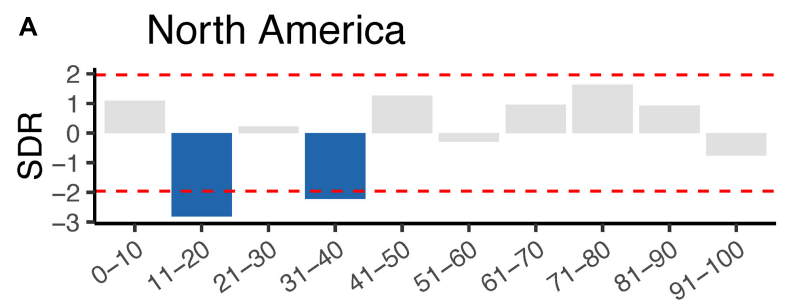

B

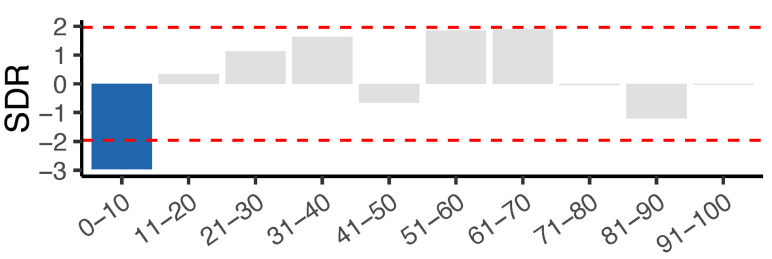

C

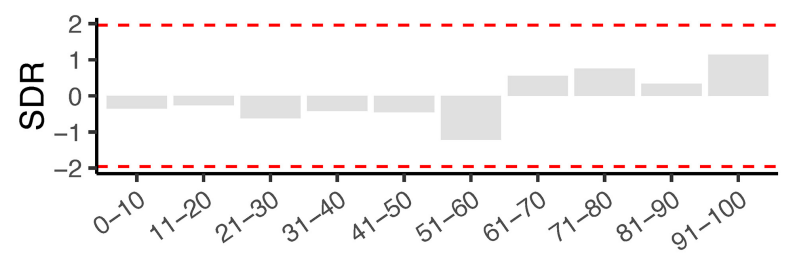

D Australia

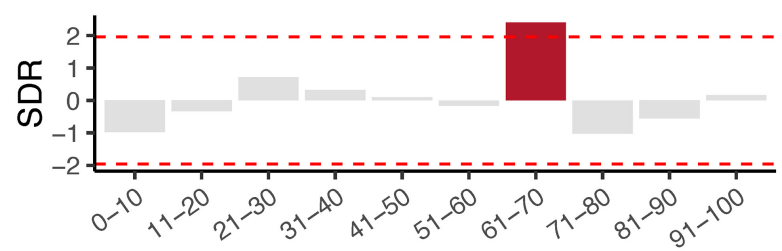

E

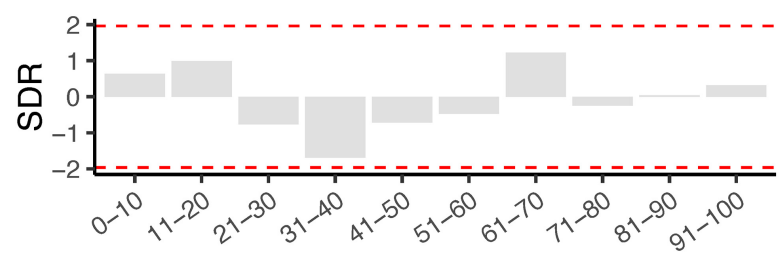

F Non-Fatal Attacks

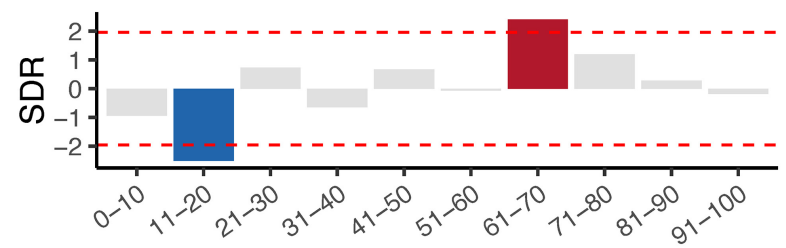

Lunar Illumination (\%)
G Bull Shark

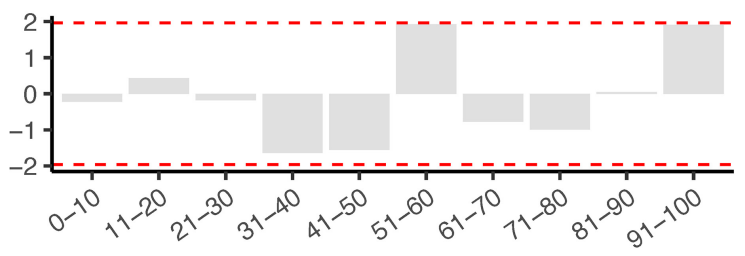

H Tiger Shark

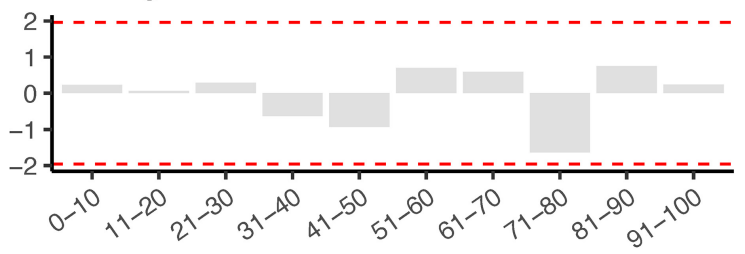

I White Shark

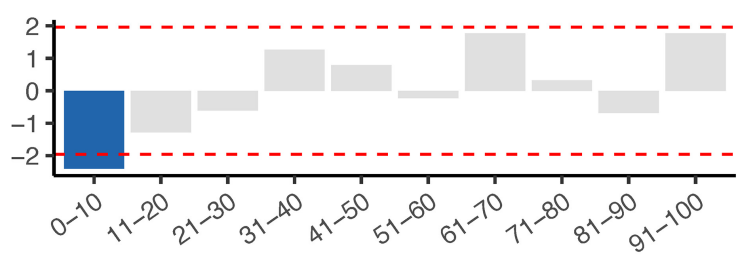

J US East Coast

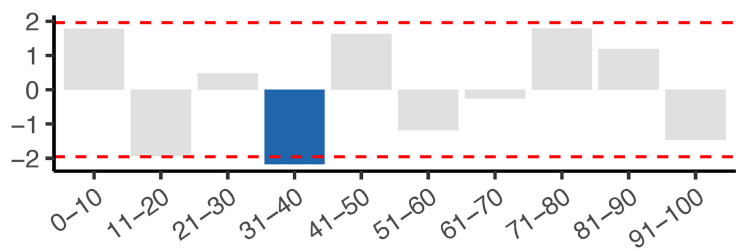

к US West Coast

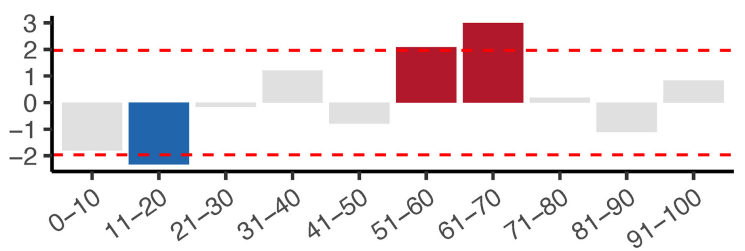

L Hawaii

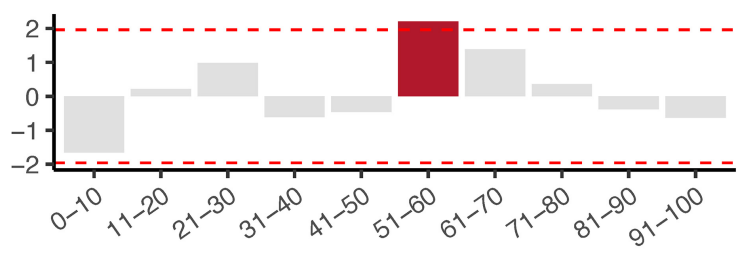

Lunar Illumination (\%)

FIGURE 3 | Standardized residuals (SDR) showing the direction and magnitude of difference between expected and observed shark attacks by lunar illumination deciles split by continental geographic regions (A-D), shark attack outcome (E,F), shark species (G-I), and United States regions (J-L). Gray bars represent SDRs that did not statistically differ from the expected count when analyzed with a Chi-squared test. Blue bars represent SDRs that were significantly less than the expected number of counts for a given lunar illumination decile, while red bars represent SDRs that were significantly greater than the expected number of counts for a given lunar illumination decile. The horizontal dashed red lines represent the cutoff for $95 \%$ significance (i.e., SDRs extending beyond the horizontal dashed red lines represented significant comparisons). 
to those groups and factors. We also acknowledge that using a 95\% significance threshold means that we might expect $5 \%$ of our results to be a false positive; however, $10 \%$ of our comparisons were significant, which exceeds a number of significant outcomes that could be considered a statistical artifact. Finally, we should note that we did not have a strong expectation that fatality would be a correlated to moon phase, but we also did not want to exclude it because it could reflect the intensity of an attack. However, we also acknowledge that a victim's fate is influenced by available medical care and other factors that are independent of the attack.

Although our study finds statistical evidence for greaterthan-expected numbers of shark attacks during lunar phases closer to the full moon, we cannot confirm a mechanism for this relationship. An interesting potential mechanism could link the changes in geomagnetic activity created by the moon to the ability of sharks to respond to electromagnetic stimuli. This magnetic hypothesis (Nishimura and Fukushima, 2009) has already been proposed at a larger scale, based on the strong evidence that geomagnetic activity increases and decreases in relation to a full moon. Bevington (2015) also describes myriad effects of lunar phase on biology while noting that lunar light alone is not enough of a mechanism to explain the observed biological changes. It is well established that sharks sense and respond to electromagnetic stimuli; e.g., electromagnetic fields are clearly important for migration behaviors (Meyer et al., 2005; Keller et al., 2021). There has not been any work linking an attack behavior (i.e., aggression or predation) to electromagnetic stimuli, yet terrestrial animal bites have been linked to lunar phase (Bhattacharjee et al., 2000) and recent work has started to connect molecular pathways with moon-controlled physiology and behaviors (Andreatta and Tessmar-Raible, 2020). Yet it is worth noting that studies reporting negative results of lunar effects also exist (e.g., Chapman and Morrell, 2000). So, while we cannot describe a mechanism for our results, we should expect to learn more about lunar geophysical/astronomical rhythms that organisms follow. For instance, it could be that while lunar phase does not directly influence shark aggression or predation, the lunar-electromagnetic cues that trigger migration or reproduction physiology may influence their subsequent trophic interactions.

Tides are another environmental variable that are influenced by moon phase and warrant future investigation regarding their potential role in shark attacks. However, for a number of reasons we did not include tides in this investigation. First, despite the same moon phase each day for the entire earth, tides are extremely variable and localized. Although tides are influenced by the moon, they are influenced by the distance from the moon and the relation of that distance to the location of the sun. Additionally, other factors, most notably local sea bottom topography and currents (Melchior, 1983) variably influence tides. For these reasons, moon phase and tide may be very correlated in some locations, and entirely uncorrelated in others. The variable and dynamic relationship between the moon and local tides would also require a large data curation effort to pair each of the thousands of shark attacks in our dataset with a specific tide. Furthermore, timing becomes an issue when considering tides. Many locations around the world experience up to two tidal cycles in a 24-hour period, which means that the exact time of day of the shark attack is critically important and simply knowing the day of attack (as often is the case in ISAF data) is not temporally resolute enough for tidal inferences. Finally, although of least importance, high and low tides in many locations change beach or water access in ways that may keep aquatic users out of the water and add an unintended local bias to underlying assumptions of recreation. We do not discount that tides may play a role in shark attacks; however, due to the fine spatio-temporal dynamics of tides, such an investigation is beyond the scope of this study.

\section{CONCLUSION}

The relationship we have reported here may not be causative, and as such we are not necessarily recommending that there are any immediate risk management benefits to our findings. Rather, we hope to underscore the complex nature of shark attacks that not only involves sharks and humans, but the wider environment. Our findings contribute to a fuller understanding of shark behavior, which may help risk management in the future. Ultimately, moon phase and lunar illumination will not likely be a strong predictor that alone can forecast risk of shark attack. Local environmental variables are expected to continue to be more practical information for assessing risk. However, the results here strongly support the idea that moon phase does play a role in overall risk of shark attack, and if future studies are able to consider local and regional environmental conditions along with lunar illumination, both understating shark attacks and forecasting risk may improve. Preventing all shark attacks worldwide remains an unlikely goal; however, continued understanding of shark biology, ecology, and environmental interactions should help to develop better estimates of attack risk and better guidelines and recommendations for human use of shark habitats.

\section{DATA AVAILABILITY STATEMENT}

Publicly available datasets were analyzed in this study. This data can be found here: https://www.floridamuseum.ufl.edu/sharkattacks/maps/.

\section{AUTHOR CONTRIBUTIONS}

LF, DE, and GB designed the study and curated the data. SM analyzed the data. LF, SM, DE, and GB drafted and revised the manuscript. All authors contributed to the article and approved the submitted version.

\section{ACKNOWLEDGMENTS}

We thank all of our worldwide colleagues who cooperate in the collection of shark attack data for inclusion to the ISAF, especially Gavin Naylor, Geremy Cliff, Randy Honebrink, Robert Lea, Christopher Lowe, Phoebe Meagher, Rodd Stapley, John West, and Sabine Wintner. 


\section{REFERENCES}

Andreatta, G., and Tessmar-Raible, K. (2020). The still dark side of the moon: molecular mechanisms of lunar-controlled rhythms and clocks. J. Mol. Biol. 432, 3525-3546. doi: 10.1016/j.jmb.2020.03.009

Baldridge, H. D. (1988). Shark aggression against man-beginnings of an understanding. Calif. Fish Game 74, 208-217.

Bevington, M. (2015). Lunar biological effects and the magnetosphere. Pathophysiology 22, 211-222. doi: 10.1016/j.pathophys.2015.08.005

Bhattacharjee, C., Bradley, P., Smith, M., Scally, A. J., and Wilson, B. J. (2000). Do animals bite more during a full moon? Retrospective observational analysis. BMJ 321, 1559-1561. doi: 10.1136/bmj.321.7276.1559

Burgess, G. H., and Callahan, M. (1996). "Worldwide patterns of white shark attacks on humans," in Great White Sharks, eds A. P. Klimley, and D. G. Ainley (London: Academic Press), 457-469. doi: 10.1016/b978-012415031-7/50043-4

Burgess, G., Buch, R. H., Carvalho, F., Garner, B. A., and Walker, C. J. (2010). "Factors contributing to shark attacks on humans: a Volusia County, Florida, case study," in Sharks and Their Relatives II: Biodiversity, Adaptive Physiology, and Conservation, eds C. J. Carrier, J. A. Musick, and M. R. Heithaus (Boca Raton, FL: CRC Press).

Chapman, S., and Morrell, S. (2000). Barking mad? Another lunatic hypothesis bites the dust. BMJ 321, 1561-1563. doi: 10.1136/bmj.321.7276.1561

Dewar, H., Mous, P., Domeier, M., Muljadi, A., Pet, J., and Whitty, J. (2008). Movements and site fidelity of the giant manta ray. Manta birostris, in the Komodo Marine Park, Indonesia. Mar. Biol. 155, 121-133. doi: 10.1007/ s00227-008-0988-x

Fallows, C., Fallows, M., and Hammerschlag, N. (2016). Effects of lunar phase on predator-prey interactions between white shark (Carcharodon carcharias) and Cape fur seals (Arctocephalus pusillus pusillus). Environ. Biol. Fishes 99, $805-812$.

Foster, S. A. (1987). Diel and lunar patterns of reproduction in the Caribbean and Pacific sergeant major damselfishes Abudefduf saxatilis and A. troschelii. Mar. Biol. 95, 333-343. doi: 10.1007/bf00409563

Graham, R. T., Roberts, C. M., and Smart, J. C. (2006). Diving behaviour of whale sharks in relation to a predictable food pulse. J. R. Soc. Interface 3, 109-116. doi: 10.1098/rsif.2005.0082

Grant, R., Halliday, T., and Chadwick, E. (2013). Amphibians' response to the lunar synodic cycle-a review of current knowledge, recommendations, and implications for conservation. Behav. Ecol. 24, 53-62. doi: 10.1093/beheco/ ars 135

Guyomard, D., Perry, C., Tournoux, P. U., Cliff, G., Peddemors, V., and Jaquemet, S. (2019). An innovative fishing gear to enhance the release of non-target species in coastal shark-control programs: the SMART (shark management alert in real-time) drumline. Fish. Res. 216, 6-17. doi: 10.1016/j.fishres.2019. 03.011

Hazin, F. H. V., Burgess, G. H., and Carvalho, F. C. (2008). A shark attack outbreak off Recife. Pernambuco, Brazil: 1992-2006. Bull. Mar. Sci. 82, 199-212.

Kaniewska, P., Alon, S., Karako-Lampert, S., Hoegh-Guldberg, O., and Levy, O. (2015). Signaling cascades and the importance of moonlight in coral broadcast mass spawning. Elife 4:e09991. doi: 10.7554/eLife.09991

Keller, B. A., Putman, N. F., Grubbs, R. D., Portnoy, D. S., and Murphy, T. P. (2021). Map-like use of Earth's magnetic field in sharks. Curr. Biol. 13, 2881-2886. doi: 10.1016/j.cub.2021.03.103

Lowry, M., Williams, D., and Metti, Y. (2007). Lunar landings-Relationship between lunar phase and catch rates for an Australian gamefish-tournament fishery. Fish. Res. 88, 15-23. doi: 10.1016/j.marenvres.2021.105456

Luecke, C., and Wurtsbaugh, W. A. (1993). Effects of moonlight and daylight on hydroacoustic estimates of pelagic fish abundance. Trans. Am. Fish. Soc. 122, $112-120$.
McCosker, J. E., and Lea, R. N. (2006). White shark attacks upon humans in California and Oregon, 1993-2003. Proc. Calif. Acad. Sci. 57, 479-501.

Melchior, P. J. (1983). The Tides of the Planet Earth. Oxford: Pergamon Press.

Meyer, C. G., Holland, K. N., and Papastamatiou, Y. P. (2005). Sharks can detect changes in the geomagnetic field. J. R. Soc. Interface 2, 129-130. doi: 10.1098/ rsif.2004.0021

Midway, S. R., Wagner, T., and Burgess, G. H. (2019). Trends in global shark attacks. PLoS One 14:e0211049. doi: 10.1371/journal.pone.0211049

Nishimura, T., and Fukushima, M. (2009). Why animals respond to the full moon: magnetic hypothesis. Biosci. Hypotheses 2, 399-401.

Ortega-Garcia, S., Ponce-Diaz, G., O'hara, R., and Merilä, J. (2008). The relative importance of lunar phase and environmental conditions on striped marlin (Tetrapturus audax) catches in sport fishing. Fish. Res. 93, 190-194.

Poisson, F., Gaertner, J. C., Taquet, M., Durbec, J. P., and Bigelow, K. (2010). Effects of lunar cycle and fishing operations on longline-caught pelagic fish: fishing performance, capture time, and survival of fish. Fish. Bull. 108, 268-281.

Prugh, L. R., and Golden, C. D. (2014). Does moonlight increase predation risk? Meta-analysis reveals divergent responses of nocturnal mammals to lunar cycles. J. Anim. Ecol. 83, 504-514. doi: 10.1111/1365-2656.12148

Ramos, J. A., Barletta, M., Dantas, D. V., Lima, A. R., and Costa, M. F. (2011). Influence of moon phase on fish assemblages in estuarine mangrove tidal creeks. J. Fish. Biol. 78, 344-354. doi: 10.1111/j.1095-8649.2010.02851.x

Ritter, E., Amin, R., and Zambesi, A. (2013). Do lunar cycles influence shark attacks? Open Fish Sci. J. 6, 71-74. doi: 10.1371/journal.pone.0068554

Takemura, A., Rahman, M. S., and Park, Y. J. (2010). External and internal controls of lunar-related reproductive rhythms in fishes. J. Fish. Biol. 76, 7-26. doi: 10.1111/j.1095-8649.2009.02481.x

Tarlow, E. M., Hau, M., Anderson, D. J., and Wikelski, M. (2003). Diel changes in plasma melatonin and corticosterone concentrations in tropical Nazca boobies (Sula granti) in relation to moon phase and age. Gen. Comp. Endocrinol. 133, 297-304. doi: 10.1016/s0016-6480(03)00192-8

Vianna, G. M., Meekan, M. G., Meeuwig, J. J., and Speed, C. W. (2013). Environmental influences on patterns of vertical movement and site fidelity of grey reef sharks (Carcharhinus amblyrhynchos) at aggregation sites. PLoS One 8:e60331. doi: 10.1371/journal.pone.0060331

West, J. G. (2011). Changing patterns of shark attacks in Australian waters. Mar. Freshw. Res. 62:744. doi: 10.1071/mf10181

Wintner, S. P., and Kerwath, S. E. (2018). Cold fins, murky waters and the moon: what affects shark catches in the bather-protection program of KwaZulu-Natal, South Africa? Mar. Freshw. Res. 69, 167-177.

Zoccola, D., and Tambutte, S. (2015). Mass spawning: sex under the moon. Elife 4:e12936. doi: 10.7554/eLife.12936

Conflict of Interest: The authors declare that the research was conducted in the absence of any commercial or financial relationships that could be construed as a potential conflict of interest.

Publisher's Note: All claims expressed in this article are solely those of the authors and do not necessarily represent those of their affiliated organizations, or those of the publisher, the editors and the reviewers. Any product that may be evaluated in this article, or claim that may be made by its manufacturer, is not guaranteed or endorsed by the publisher.

Copyright (c) 2021 French, Midway, Evans and Burgess. This is an open-access article distributed under the terms of the Creative Commons Attribution License (CC BY). The use, distribution or reproduction in other forums is permitted, provided the original author(s) and the copyright owner(s) are credited and that the original publication in this journal is cited, in accordance with accepted academic practice. No use, distribution or reproduction is permitted which does not comply with these terms. 